\title{
Small Ruminant Brucellosis and Public Health Awareness in Two Districts of Afar Region, Ethiopia
}

Anteneh Hailu Tegegn ${ }^{1}$, Aklilu Feleke ${ }^{2}$, Wesinew Adugna ${ }^{3}$ and Simenew Keskes Melaku*

${ }^{1}$ Semeral Veterinary Regional Laboratory, Afar, Ethiopia

${ }^{2}$ College of Veterinary Medicine and Agriculture, Addis Ababa University, PO Box 34, Bishoftu, Ethiopia

${ }^{3}$ VSF Suisse, Addis Ababa, Ethiopia

${ }^{4}$ College of Agriculture and Natural Resources, Dilla University, PO Box 419, Dilla, Ethiopia

\begin{abstract}
Cross-sectional serological and questionnaire surveys were employed on small ruminants to determine the prevalence of brucellosis, identify risk factors and public health implications. Brucellosis is a bacterial disease with high economic and public health importance in the sub-Sahara countries in particular. A total of 1190 blood samples were collected from shoats (876 caprine and 314 ovine) in Chifra and Ewa districts. One hundred fifty five (13\%) of the samples tested were positive using mRBPT. Further testing of the positive reactors for mRBPT with CFT revealed $147(12.35 \%)$ seropositivity for brucella. The result showed that among the risk factors considered in the analysis, species, sex, age, parity number and flock size had statistically significant effect on seropositivity $(p<0.05)$. Goats were more than 2 times $(\mathrm{OR}=2.34)$ at risk of getting infected with brucella than sheep. The seroprevalence was also significantly higher in female $(13.8 \%)$ than in male $(6.5 \%)$ animals. The odds of seropositivity in older animals are 2.36 times higher than that of younger ones. Individual animal seroprevalence was higher in larger flocks than in smaller ones $(\mathrm{OR}=0.68)$. The habit of drinking raw milk was practiced by almost all of the respondents. Poor awareness of the zoonotic importance of brucellosis and the practices of consuming raw milk and handling potentially infectious materials using bare hands pose a serious danger to small ruminant owners. There is a need for planning and implementation of joint programs by stakeholders in prevention and control of the disease as well as raising public awareness.
\end{abstract}

Keywords: Afar region; Brucellosis; CFT; Public health; RBPT; Small ruminants

\section{Introduction}

Brucellosis is a zoonotic bacterial disease caused by Brucella species and is primarily a disease of animals and humans are accidental hosts [1]. The disease is an important public health problem but neglected in many parts of the world [1-3]. The disease is more important in developing countries and has important economic and public health consequences [3]. Brucellosis has been virtually eradicated from majority of developed countries; but important disease among livestock and people in sub-Saharan Africa [4].

Infection in animals is strongly correlated with abortions in the last trimester of pregnancy and commonly affected animals include bovine, ovine, caprine, swine, and some other domestic animals including camels [3,5]. In animals, the primary sign of infection in females is abortion and in males epididymitis and orchitis and diagnosis can only be confirmed by laboratory tests that may even confirm latent infections [1]. Cross-transmission of brucellosis can occur among cattle, sheep, goats, camels and other species [6].

Brucellosis is a major cause of direct economic losses resulting from clinical disease, abortion, neonatal losses, reduced fertility, decreased milk production, emergency slaughtering of the infected animals and treatment costs. It also plays a significant role as a barrier for international trade of live animals by being used as an impediment to free animal movement and export [7]. Economic losses in small ruminants stem from breeding inefficiency, loss of lambs and kids, reduced wool, meat and milk production [8].

In Africa, little is known about its epidemiological status in animals and neither the factors contributing to its cross-species nor to human transmission [9]. The huge and diverse livestock species in Ethiopia are kept under different agro-ecological zones, management systems, migration and animal health care system. The predominant extensive husbandry practices of the country provide ample opportunities for mixing of different animal species at communal grazing areas and watering points [10].

More importantly, a close human-animal contact and tradition of raw animal product consumption make zoonosis among the major public health hazards, with particular implication to pastoral area. This requires a thorough epidemiological investigations including due consideration to identifying the major risk factors that predominantly influence the disease occurrence, and thus contribute to design appropriate and feasible national controlling strategies. Brucellosis in sheep and goats mainly caused by Brucella melitensis is characterized by abortion, stillbirths and reproductive failure. According to AU-IBAR [11], small ruminants' brucellosis was not reported from Ethiopia, although high prevalence rate of up to 13.6 by Wesinew et al. [5] in small ruminants. In Afar region very little attempts were done and there were no such studies yet in the current target districts. Therefore, this study is designed with the objectives to determine prevalence of brucellosis in small ruminants and its public health impact in Ewa and Chifra districts and to identify risk factors and sources of infection for livestock and humans.

${ }^{*}$ Corresponding author: Simenew Keskes Melaku, College of Agriculture and Natural Resources, Dilla University, PO Box 419, Dilla, Ethiopia, Tel: +251911364193; E-mail: drsimenew@yahoo.com or simenew.keskes@aau.edu.et

Received April 04, 2016; Accepted May 11, 2016; Published May 16, 2016

Citation: Tegegn AH, Feleke A, Adugna W, Melaku SK (2016) Small Ruminan Brucellosis and Public Health Awareness in Two Districts of Afar Region, Ethiopia J Vet Sci Technol 7: 335. doi:10.4172/2157-7579.1000335

Copyright: (c) 2016 Tegegn $\mathrm{AH}$, et al. This is an open-access article distributed under the terms of the Creative Commons Attribution License, which permits unrestricted use, distribution, and reproduction in any medium, provided the original author and source are credited. 


\section{Materials and Methods}

\section{Study area}

The study was carried out in two districts namely Chifra and Ewa, located in Zone one and Zone four respectively of Afar National Regional State (ANRS). Chifra and Ewa districts are found 174 and 219 kilometer far from Semera town respectively. The districts are found adjacently and share boundary with Amhara region. Chifra district has 1 urban and 19 rural peasant associations while Ewa contains 1 urban and 9 rural peasant associations. May/June is the driest season of the year, 'hagay'. It is said to be unsuitable for browsing since bushes dry up. The main rainy season 'Karma', accounts for above $60 \%$ of the annual total rainfall are from July to September. This is followed by the best grazing season of 'Kayra' that occurs from September to November. Another minor rainy season is Sugum and appears during March and April. 'Gilal' is less severe dry season with relatively cool temperatures (November to March). Occasional rainfalls called dada may interrupt 'Gilal' [12].

\section{Study animals}

The study animals were indigenous Afar goat and sheep characterized by ILRI [13]. Ovine and caprine which were above 6 months of age with no history of vaccination against brucellosis were included in the study. Then individual animal age, species, sex, flock size and parity were recorded. The study animals consisted of 1190 traditionally managed small ruminants of which 146 ovine and 214 caprine were obtained from Ewa district while the remaining 168 ovine and 662 caprine were obtained from Chifra district.

\section{Study design and sampling strategies}

A cross-sectional study design was devised from November 2013 to April 2014 to determine the seroprevalence of brucellosis in sheep and goats from the two selected study districts. Two districts were selected purposively based on easier accessibility as well as ovine and caprine populations. At the present, there are 20 and 10 PAs in Chifra and Ewa districts, respectively. Peasant associations in the districts were selected simple randomly in the ratio of 2:1 (Chifra (6) and Ewa (3) districts, respectively). Peasant association is the lowest administrative unit within a district considered. A total of 1,190 sera samples were collected from 45 flocks of small ruminants.

Two districts from zone one and zone four of the existing five zones were selected purposively; and a multistage random sampling method were used to select the sampling units. Households were the sampling units and the principles of simple random sampling technique to select peasant associations and systematic random sampling to sample the households were followed at each stage of sampling. The numbers of animals included in the study were distributed proportionally over the PAs.

\section{Sample size determination}

The total number of animals to be sampled were calculated using Win Episcope 2.0, an improved epidemiological software for veterinary medicine developed for simple random sampling with the under mentioned assumption and an infinite population and inflated the estimated sample size to 1190 small ruminants [14]. A 5\% absolute precision and $95 \%$ confidence interval were used for determining sample size. Since previous study in the region indicated that prevalence rate of $5.7 \%$ (Chifra) and $2.4 \%$ (Ewa), an expected prevalence of $20 \%$ were used to obtain the maximum sample size. Accordingly, 246 animals were the calculated sample size for each Chifra and Ewa district. In order to get representative sample for both districts inflated the sample size to 1190 . Therefore; the appropriate sample sizes were 830 and 360 ovine and caprine for Chifra and Ewa district respectively. In general 1190 sera samples were collected from 45 flocks of small ruminants.

$$
n=\frac{1.96^{2} \times P_{\exp }(1-P)}{d^{2}}
$$

Where $\mathrm{n}=$ the total sample size

$\mathrm{P}=$ expected prevalence

$\mathrm{d}^{2}=$ absolute precision

\section{Methodologies}

Questionnaire survey: A structured questionnaire was administered to livestock owners/herders men after pretesting in the field properly and translated to the local language 'Afarigna'. Verbal consent was obtained from the respondents after the objective of the survey is explained to them before starting the interview. This questionnaire was designed for a survey of the potential risk factors associated with the disease in their flocks and to gather relevant information on the overall small ruminants' management practices, knowledge about zoonotic diseases, habit of consuming animal products, handling of aborted fetuses and other potentially contaminated materials.

Serological survey: Approximately $8 \mathrm{ml}$ of blood from jugular vein of sheep and goats were collected aseptically using sterile plain vacutainer tubes. The samples were properly labelled and left for overnight at room temperature to allow clotting and the sera were decanted and stored in sterile Eppendorf tubes at $-20^{\circ} \mathrm{C}$ in Samara Regional Veterinary Laboratory until tested for antibodies in National Veterinary Institute.

Modified Rose Bengal Plate Test (mRBPT): All sera samples collected were screened using the RBPT, according to the procedures described by Alton et al. [15] and the World Organisation for Animal Health [16,17]. This test was done at Semera Regional Veterinary Laboratory in order to screen positive samples by RBPT using RBPT antigen (Institue Pourquier 325, rue de la galèra 34097 Montpellier cedex 5, France). Positive sera were then retested using complement fixation test (CFT) at the National Veterinary Institute.

In brief, $75 \mu \mathrm{l}$ of serum was mixed with $25 \mu \mathrm{l}$ of antigen suspension on a glass plate and agitated. After four minutes of rocking, any visible agglutination was considered as positive [16]. Agglutinations were recorded as $0,+,++$ and +++ , according to the degree of agglutination. A score of 0 indicates the absence of agglutination; + indicates barely visible agglutination; ++ indicates fine agglutination, and +++ indicates coarse clumping. Those samples with no agglutination (0) were recorded as negative while those with,+++ and +++ were recorded as positive [17].

Complement Fixation Test (CFT): All the reagents required for CFT were evaluated by titration. Positive sera with RBPT were further tested with CFT for confirmation using standard B. abortus antigen (New Haw, Addleston, and Surrey KT15 3NB, UK). The CFT test proper and reagent preparation procedures were following the procedures outlined by Ref. [16]. Sera with strong reaction, more than $75 \%$ fixation of complement $(3+)$ at a dilution of $1: 5$ or at least with $50 \%$ fixation of complement $(2+)$ at a dilution of $1: 10$ and above were classified as positive [16].

\section{Statistical analyses}

Data obtained from both serological tests and questionnaire surveys were stored in Microsoft excel spreadsheet program. Descriptive and 
Citation: Tegegn AH, Feleke A, Adugna W, Melaku SK (2016) Small Ruminant Brucellosis and Public Health Awareness in Two Districts of Afar Region, Ethiopia. J Vet Sci Technol 7: 335. doi:10.4172/2157-7579.1000335

Page 3 of 5

analytic statistics were computed using SPSS Version 20.0. Logistic regression was employed to identify possible risk factors associated with seropositivity in sheep and goats. The degree of association was computed using odds ratio (OR) signified by $95 \%$ confidence intervals [14].

\section{Results}

\section{Individual and flock level seroprevalence of brucellosis}

The highest individual animal level seroprevalence was recorded in goat from species group in both Chifra and Ewa woredas. The overall flock level seroprevalence of brucellosis infection was $57.8 \%$ while it was $60 \%$ and $53.3 \%$ in Chifra and Ewa district respectively. The difference in seropositivity between species in both woredas was statistically significant $(\mathrm{p}<0.05)$ as presented in Table 1.

\section{Risk factors affecting individual animal level seroprevalence of brucellosis}

The results revealed that among the risk factors considered in the analysis, species, sex, age, parity number and flock size had statistically significant effect on seropositivity $(\mathrm{p}<0.05)$ as indicated in Table 2.

The risk factors with significant effect after univariate logistic regression test (species, sex, age, parity and flock size) were fitted in a multivariate model and the results showed that all the factors except districts had statistically significant effect on the seroprevalence of brucellosis in sheep and goat populations $(\mathrm{p}<0.05)$ (Table 3). Age

\begin{tabular}{|c|c|c|c|c|c|c|c|}
\hline \multirow[b]{2}{*}{ Zone } & \multirow[b]{2}{*}{ District } & \multirow[b]{2}{*}{ Species } & \multirow[b]{2}{*}{ No. Tested } & \multirow{2}{*}{ CFT positive } & \multirow[b]{2}{*}{ p-value } & \multicolumn{2}{|c|}{ Flock level } \\
\hline & & & & & & $\begin{array}{c}\text { No } \\
\text { tested }\end{array}$ & $\begin{array}{c}\text { Positive } \\
\text { (\%) }\end{array}$ \\
\hline & Chifra & Overall & 830 & $104(12.5 \%)$ & 0.018 & \multirow{2}{*}{30} & \multirow{2}{*}{$18(60 \%)$} \\
\hline \multirow[t]{3}{*}{1} & & Ovine & 168 & $12(7.14 \%)$ & & & \\
\hline & & Caprine & 662 & $92(13.8 \%)$ & & & \\
\hline & Ewa & Overall & 360 & $43(12.0 \%)$ & 0.005 & 15 & $8(53.3 \%)$ \\
\hline \multirow[t]{2}{*}{4} & & Ovine & 146 & $9(6.16 \%)$ & & & \\
\hline & & Caprine & 214 & 34 (15.89\%) & & & \\
\hline
\end{tabular}

Table 1: Individual animal and flock level seroprevalence of brucellosis in sheep and goat populations in Chifra and Ewa woredas, Afar Region.

\begin{tabular}{|c|c|c|c|c|c|}
\hline Risk factors & Category & Prevalence & OR & $95 \% \mathrm{Cl}$ & $p$-value \\
\hline \multirow[t]{2}{*}{ Woreda } & ${ }^{*} 1$ (Chifra) & $12.5 \%$ & \multirow[b]{2}{*}{0.947} & \multirow{2}{*}{$0.648-1.383$} & \multirow{2}{*}{0.778} \\
\hline & 4 (Ewa) & $12 \%$ & & & \\
\hline \multirow[t]{2}{*}{ Species } & ${ }^{*}$ Ovine & $6.7 \%$ & \multirow{2}{*}{2.34} & \multirow{2}{*}{$1.44-3.79$} & \multirow{2}{*}{0.001} \\
\hline & Caprine & $14.4 \%$ & & & \\
\hline \multirow[t]{2}{*}{ Sex } & "Male & $6.5 \%$ & \multirow[b]{2}{*}{2.12} & \multirow{2}{*}{$0.24-0.75$} & \multirow{2}{*}{0.003} \\
\hline & Female & $13.8 \%$ & & & \\
\hline \multirow[t]{3}{*}{ Age/Years } & ${ }^{*}<2$ years & $2.8 \%$ & \multirow{3}{*}{$\begin{array}{c}5.86 \\
7.1\end{array}$} & \multirow{3}{*}{$1.84-3.02$} & \multirow{3}{*}{0.000} \\
\hline & $2-5$ years & $16.4 \%$ & & & \\
\hline & $>5$ years & $20 \%$ & & & \\
\hline \multirow[t]{3}{*}{ Parity } & ${ }^{*} 0$ & $1.3 \%$ & \multirow{3}{*}{$\begin{array}{c}7.7 \\
16.9\end{array}$} & \multirow{3}{*}{$1.07-1.56$} & \multirow{3}{*}{0.006} \\
\hline & $1-2$ & $10.2 \%$ & & & \\
\hline & $3-4$ & $22 \%$ & & & \\
\hline \multirow[t]{2}{*}{ Flock size } & ${ }^{*} \leq 25$ & $36.8 \%$ & \multirow[b]{2}{*}{1.93} & \multirow[t]{2}{*}{$0.46-0.99$} & \multirow{2}{*}{0.011} \\
\hline & $>25$ & $73 \%$ & & & \\
\hline
\end{tabular}

"Reference category; OR: Odds ratio; Cl: Confidence interval

Table 2: Results of univariate logistic regression analysis of risk factors.

\begin{tabular}{|c|c|c|c|}
\hline CFT & Odds Ratio & $\mathbf{( 9 5 \%}$ Cl) & p-value \\
\hline Species & 2.131 & $1.53-3.44$ & 0.003 \\
\hline Sex & 0.138 & $0.059-0.321$ & 0.000 \\
\hline Parity & 2.038 & $1.303-3.187$ & 0.002 \\
\hline Flock size & 0.761 & $0.684-1.523$ & 0.011 \\
\hline
\end{tabular}

Table 3: Multivariate logistic regression analysis of risk factors of brucellosis in small ruminants.

\begin{tabular}{|c|c|c|c|c|c|c|}
\hline $\begin{array}{c}\text { Risk } \\
\text { factors }\end{array}$ & Category & Number & Infected & (95\% Cl) & p-value & OR \\
\hline Flock size & $\leq 25$ & 19 & 7 & $0.46-0.99$ & 0.011 & 0.68 \\
\hline & $>25$ & 26 & 19 & & & \\
\hline Districts & Chifra & 30 & 18 & $0.648-1.383$ & 0.778 & 0.947 \\
\hline & Ewa & 15 & 8 & & & \\
\hline
\end{tabular}

OR: Odds ratio; $\mathrm{Cl}$ : Confidence interval

Table 4: Risk factors associated with seroprevalence occurrence at flock level of small ruminants.

was dropped from the multivariate model due to the likelihood of confounding the effects of parity. The results of univariate logistic regression analysis are presented in Table 4.

\section{Risk factors affecting the flock level seroprevalence of brucellosis}

Seroprevalence of brucellosis was statistically significant in larger sized flocks than in smaller ones and in Chifra than in Ewa $(p<0.05)$ as stipulated in Table 4.

\section{Public health importance of brucellosis}

The results of the questionnaire survey on the perception and practices of livestock owners in the study areas are presented below. Most of the outcomes of the analysis of the questionnaire data showed that livestock owners in the studied areas are at high risk of contracting brucellosis from infected animals. Almost all the respondents in the studied areas were not aware of brucellosis as a disease affecting different species of livestock (91.1\%) although all respondents (45 livestock owners) interviewed recognized the existence of abortion (locally called in Afarigna as "Feneg-dalay") among small ruminant flocks and most of them handle abortion materials with bare hand without protecting themselves (82.2\%). The habit of drinking raw milk is practiced by all the 45 interviewed respondents (100\%) while there is no habit of consuming raw meat.

\section{Discussion}

The flock level prevalence is higher than individual animal level and this characterizes the nature and importance of the disease in the large flock size. This signifies that brucellosis has significant economic implication in its ability to bring about morbidity at flock level. Above all the higher flock level prevalence can be considered as a serious public health concern. The study also demonstrated overall individual animal level seroprevalence of brucellosis in small ruminant was 12.35\% (95\% CI: 1.44-3.79). This is fairly comparable to the seroprevalence reported in Afar region by Ref. $[5,18]$. Since there is barely no vaccination or any other control mechanisms in the region increasing trend of prevalence is expected. Above all free movement and mixing of different herds and among species can also facilitate transmission and cross infection [19]. However, the current prevalence is lower than report by Al-Majali [20] (27.7\%) and Hamidullah et al. [21] (34.88\%) in Jordan. The reason for this discrepancy could be variation in management practices and level of frequent introduction of new animals. The prevalence in this study is 
higher than the findings by Tekleye and Kasali [22] in central highlands of Ethiopia. This could be due to the production system difference as mixed crop-livestock management is practiced in the latter.

There was statistical significant difference between ovine and caprine species. The higher seroprevalence of brucellosis in caprine $14.4 \%$ than in ovine $6.7 \%$ was comparable with Ref. [5]. This species prevalence difference might be due to the fact that ovine are more resistant than caprine and they do not shade the bacteria for long time and flocks with high numbers of ovine would have low prevalence [23]. Above all, caprine are the principal host of $B$. melitensis, whereas, ovine are not significantly infected even when kept in close contact with caprine [24]. In addition, infection in caprine can vary from acute to persistent occurrence for years whereas in ovine, the course of infection depends upon the dose of bacteria and they are resistant to re-infection.

There was statistical significant difference between male and female small ruminants in the current study. The higher seroprevalence of brucellosis in females (13.8\%) than in male (6.5\%) might be due to high concentration of erythritol, which is scarcely produced in male reproductive organs [25]. In addition, the Afar society supply male small ruminants to both the export and domestic markets while female small ruminants are used as replacement herd just like all pastoralists.

Animals with three or more parities showed significantly higher seroprevalence than animals with less than 3 parities. A statistically significant variation was also recorded between adults and young animals. It has been reported that brucellosis is essentially a disease of sexually mature animals [26]. Sexually mature and pregnant animals are more prone to Brucella infection and brucellosis than sexually immature animals of either sex [23]. On the other hand, it is also true that younger animals tend to be more resistant to infection and frequently clear an established infection, although latent infections can occur [27]. This may result from the hormone erythritol, which stimulate the growth and multiplication of Brucella organisms, tend to increase in concentration with age and sexual maturity [23]. No significant difference was seen between the two districts, since the similarity in agro-ecological conditions and livestock management system.

From the questionnaire survey, almost all small ruminant owners residing in the study area were able to recognize the occurrence of abortion in their flocks. More than $86 \%$ of the respondents had the habit of drinking raw milk and $82.2 \%$ of the respondents used to dispose of aborted fetuses barehanded. This may be due to lack of awareness about brucellosis together with existing habit of raw milk consumption and close contact between animals and humans.

\section{Conclusions}

Results of the present study show the importance of small ruminant brucellosis in Afar pastoral areas and identify the risk factors that contribute to the occurrence of the disease possible zoonotic implications. Critical assessment of the economic impact of the disease, which emanates from its effect on reproductive and production performance of animals, is worthy as the prevalence is high. Joint ventures among veterinary and public health professionals are of paramount importance to control this disease. Awareness creation among pastoralists on animal husbandry, disease prevention and risk of zoonotic diseases need to be undertaken. Large scale investigation level of infection in both animals and humans at risk should be done in Afar. Further studies focused on the isolation and molecular characterization of the circulating Brucella species is imperative.

\section{References}

1. Corbel MJ (2006) Brucellosis in humans and animals. World Health Organization, Geneva.

2. Hadush A, Pal M (2013) Brucellosis-An infectious re-emerging bacterial zoonosis of global importance. Int J Livest Res 3: 28-34.

3. Bekele WA, Tessema TS, Melaku SK (2013) Camelus dromedarius brucellosis and its public health associated risks in the Afar National Regional State in northeastern Ethiopia. Acta Vet Scand 55: 89.

4. Franco MP, Mulder M, Gilman RH, Smits HL (2007) Human brucellosis. Lancet Infect Dis 7: 775-786.

5. Adugna W, Tessema TS, Keskes S (2013) Sero-prevalence of small ruminants brucellosis in four districts of Afar National Regional State, Northeast Ethiopia. Journal of Veterinary Medicine and Animal Health 5: 358-364.

6. Dawood HA (2008) Brucellosis in Camels (Camelus dromedorius) in the south province of Jordan. Am J Agri Biol Sci 3: 623-626.

7. Coelho AM, Coelho AC, Roboredo M, Rodrigues J (2007) A case-control study of risk factors for brucellosis seropositivity in Portuguese small ruminants herds. Prev Vet Med 82: 291-301.

8. Renukaradhya GJ, Isloor S, Rajasekhar M (2002) Epidemiology, zoonotic aspects, vaccination and control/eradication of brucellosis in India. Vet Microbiol 90: 183-195.

9. Megersa B, Biffa D, Niguse F, Rufael T, Asmare K, et al. (2011) Cattle brucellosis in traditional livestock husbandry practice in Southern and Eastern Ethiopia, and its zoonotic implication. Acta Vet Scand 53: 24.

10. Muma JB, Samui KL, Oloya J, Munyeme M, Skjerve E (2007) Risk factors for brucellosis in indigenous cattle reared in livestock-wildlife interface areas of Zambia. Prev Vet Med 80: 306-317.

11. AU-IBAR (2013) Brucella melitensis Infection. Know your animals' monthly series.

12. Afar Region Finance and Economy Bureau (ARFEB) (2007) Regional atlas of Afar region, Semera, Ethiopia.

13. International Livestock Research Institute (2006) Domestic animal genetic resources information system (DAGRIS) (Rege JEO, Ayalew W, Getahun E Hanotte O, Dessie T), Addis Ababa, Ethiopia.

14. Thrusfield M (2007) Veterinary Epidemiology. Blackwell science Ltd., USA, pp: 228-242.

15. Alton GG (1990) Brucella melitensis. In: Animal Brucellosis. Nielsen K and Duncan R (eds). CRC Press, Boca Raton, Florida, USA, pp: 383-409.

16. Díez FG, León FC (2004) The Spanish translation of the Manual of Diagnostic Tests and Vaccines for Terrestrial Animals: current and future solutions. Rev Sci Tech 23: 1023-1031.

17. Nielsen K, Dunkan JR (1990) Animal Brucellosis. CRC Press Inc., USA, pp 173-179.

18. Teshale S, Muhie Y, Dagne A, Kidanemariam A (2006) Seroprevalence of small ruminant brucellosis in selected districts of Afar and Somali pastoral areas of Eastern Ethiopia: the impact of husbandry practice. Revue Med Vet 157: $557-$ 563.

19. Sharifi H, Mashayekhi K, Tavakoli MM (2015) Risk facts of small ruminant brucellosis: a crosssectional study in Southeast Iran 2012. Human \& Veterinary Medicine. International Journal of the Bioflux Society 7: 42-45.

20. AI-Majali AM (2005) Seroepidemiology of caprine brucellosis in Jordan. Small Rumin Res 58: 13-18.

21. Hamidullah M, Khan R, Khan I (2009) Seroprevalence of brucellosis in animals in district Kohat NWFP and comparison of two serological tests. Pak Vet $\mathrm{J} 4$ 242-243.

22. Bekele T, Kasali OB (1990) Brucellosis in sheep and goats in Central Ethiopia. Bull Anim Health Prod Afr 38: 23-25.

23. Radostits OM, Gay CC, Hinchcliff KW, Constable PD (2007) Veterinary Medicine: A textbook of the diseases of cattle, sheep, goats, pigs, and horses. 10th edn. Saunders Company, Philadelphia, USA, pp: 962-984.

24. Alton GG (1985) Epidemiology of $B$. melitensis in sheep and goats. In: $B$. 
Citation: Tegegn AH, Feleke A, Adugna W, Melaku SK (2016) Small Ruminant Brucellosis and Public Health Awareness in Two Districts of Afar Region, Ethiopia. J Vet Sci Technol 7: 335. doi:10.4172/2157-7579.1000335

melitensis CEC seminar. Verger JM, Plommet $\mathrm{M}$ (eds.). Martinus Nijoff, Dordrecht-Bosten Lancaster, pp: 187-196

25. Colmenero JD, Muñoz-Roca NL, Bermudez P, Plata A, Villalobos A, et al. (2007) Clinical findings, diagnostic approach, and outcome of Brucella melitensis epididymo-orchitis. Diagn Microbiol Infect Dis 57: 367-372.
26. Osman AY, Jesse FF, Abdulkadir A, Saharee AA (2016) The Epidemiology and Immunopathophysiology of Brucellosis in Small Ruminant. PJSRR 2: 11-21.

27. Walker R (1999) Brucella. In: Veterinary Microbiology and Immunology. Hirsh DC, Zee YC (Eds.). Blackwell Science, USA, pp: 196-202. 